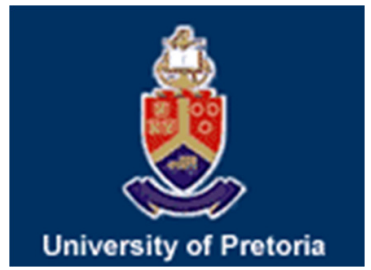

\author{
University of Pretoria \\ Department of Economics Working Paper Series
}

The Impact of the 2014 Platinum Mining Strike in South Africa: An EconomyWide Analysis

Heinrich R. Bohlmann

University of Pretoria

Peter B.Dixon

Victoria University

Maureen T. Rimmer

Victoria University

Jan van Heerden

University of Pretoria

Working Paper: 2014-72

November 2014

Department of Economics

University of Pretoria

0002, Pretoria

South Africa

Tel: +27 124202413 


\title{
The Impact of the 2014 Platinum Mining Strike in South Africa: An Economy-Wide Analysis
}

\author{
Bohlmann, H.R., Dixon, P.B., Rimmer, M.T. and Van Heerden, J.H.
}

November 12, 2014

\begin{abstract}
In this paper we measure the economy-wide impact of the 2014 labour strike in South Africa's platinum industry. The strike lasted five months, ending in June 2014 when producers reached an agreement with the main labour unions. The immediate impacts on local mining towns were particularly severe, but our research shows that the strike could also have long lasting negative impacts on the South African economy as a whole. We find that it is not the higher nominal wages itself that caused the most damage, but the possible reaction by investors in the mining industry towards South Africa. Investor confidence is likely to be, at least, temporarily harmed, in which case it would take many years for the effects of the strike to disappear. We conduct our analysis using a dynamic CGE model of South Africa.
\end{abstract}

JEL codes: C68, J52

Keywords: Platinum mining strike, computable general equilibrium, UPGEM

\section{Introduction}

The labour strike in South Africa's platinum sector that started on 23 January 2014 became the country's largest and most expensive in history. The dispute regarding wages and conditions of service between the Association of Mineworkers and Construction Union (AMCU) and the main platinum producers lasted five months, with an agreement eventually reached on 24 June 2014. The mines directly affected included Anglo American Platinum Limited (Amplats), Impala Platinum Holding Limited (Implats) and Lonmin Plc (Lonmin), the three largest platinum producers in South Africa and the world. According to a joint statement from the platinum producers, the strike reportedly affected half of the global platinum supply in which employers forfeited revenue of approximately R23 billion and employees lost earnings of some R10.7 billion. Whilst these direct effects are relatively easy to estimate, it is harder to predict the total economy-wide impact of the shock over an extended period of time.

For this study we use a dynamic computable general equilibrium (CGE) model to estimate the economy-wide impact of the platinum sector strike in 
South Africa over the period 2014 to 2020. Four different simulations are run, ranging from the most optimistic scenario to the most damaging with regard to the expected future impact of the strike.

The structure of the paper is as follows. Section 2 briefly describes our methodology, including a description of the model and database. Section 3 describes the baseline and four strike simulations, and interprets the subsequent results. Section 4 concludes the paper with an overview of the findings.

\section{Methodology}

We use the University of Pretoria General Equilibrium Model (UPGEM) to conduct our analysis of the platinum sector strike on the South African economy. CGE models such as UPGEM provide industry-level disaggregation in a quantitative description of the whole economy and postulate neo-classical production functions and price-responsive demand functions, linked around a supply-use matrix in a general equilibrium model that endogenously determines prices and quantities.

Four basic tasks distinguish CGE based analysis (Adams, 2005). First is the theoretical derivation and description of the model. UPGEM is based on the well-documented MONASH model described in Dixon \& Rimmer (2002) and Dixon, Koopman \& Rimmer (2013). Following the MONASH-style of implementing a CGE model, the general equilibrium core of UPGEM is made up of a linearized system of equations describing the theory underlying the behaviour of participants in the economy. It contains equations describing, amongst others: the nature of markets; intermediate demands for inputs to be used in the production of commodities; final demands for goods and services by households; demands for inputs to capital creation and the determination of investment; government demands for commodities; and foreign demand for exported goods. The model is implemented and solved using RunDynam in the GEMPACK suite of programs described in Harrison \& Pearson (1996). GEMPACK eliminates linearization errors by implementing shocks in a series of small steps and updating the database between steps.

The specifications in UPGEM recognise each industry as producing one or more commodities, using as inputs combinations of domestic and imported commodities, different types of labour, capital and land. The multi-input, multioutput production specification is kept manageable by a series of separability assumptions, illustrated in Figure A1 of the Appendix. This nested production structure reduces the number of estimated parameters required by the model. Optimising equations determining the commodity composition of industry output are derived subject to a CET function, while functions determining industry inputs are determined by a series of CES nests. At the top level of this nesting structure intermediate commodity composites and a primary-factor composite are combined using a Leontief or fixed-proportions production function. Consequently, they are all demanded in direct proportion to industry output or activity. Each commodity composite is a CES function of a domestic good and 
its imported equivalent. This incorporates Armington's assumption of imperfect substitutability for goods by place of production (Armington, 1969). The primary-factor composite is a CES aggregate of composite labour, capital and, in the case of primary sector industries, land. Composite labour demand is itself a CES aggregate of the different types of labour distinguished in the model's database. In UPGEM, all industries share this common production structure, but input proportions and behavioural parameters vary between industries based on base year data and available econometric estimates, respectively.

The demand and supply equations in UPGEM are derived from the solutions to the optimisation problems which are assumed to underlie the behaviour of private sector agents in conventional neo-classical microeconomics. Each industry minimises cost subject to given input prices and a constant returns to scale production function. Zero pure profits are assumed for all industries. Households maximise a Klein-Rubin utility function subject to their budget constraint. Units of new industry-specific capital are constructed as cost-minimising combinations of domestic and imported commodities. The export demand for any locally produced commodity is inversely related to its foreign-currency price. Government consumption, typically set exogenously in the baseline or linked to changes in household consumption in policy simulations, and the details of direct and indirect taxation are also recognised in the model.

The recursive-dynamic behaviour in UPGEM is specified through equations describing: physical capital accumulation; lagged adjustment processes in the labour market; and changes in the current account and net foreign liability positions. Capital accumulation is specified separately for each industry and linked to industry-specific net investment in the preceding period. Investment in each industry is positively related to its expected rate of return on capital, reflecting the price of capital rentals relative to the price of capital creation. For the government's fiscal accounts, a similar mechanism for financial asset/liability accumulation is specified. Changes in the public sector debt are related to the public sector debt incurred during a particular year and the interest payable on previous debt. Adjustments to the national net foreign liability position are related to the annual investment/savings imbalance, revaluations of assets and liabilities and remittance flows during the year. In policy simulations, the labour market follows a lagged adjustment path where wage rates respond over time to gaps between demand and supply for labour across each of the different occupation groups.

The second task identified by Adams (2005) is calibration, which incorporates the construction of a balanced database and evaluation of coefficients and parameters. As required for MONASH-style models, the initial levels solution of the model is provided by the base year data. The database, in combination with the model's theoretical specification, describes the main real inter-linkages in the South African economy. The theory of the model is then, essentially, a set of equations that describe how the values in the model's database move through time and move in response to any given policy shock. The current version of UPGEM uses a 2011 reference year database that draws mainly from the 2011 supply-use tables published in StatsSA (2014a) and other data in SARB (2014). 
The standard database distinguishes 40 industries and commodities, and 11 occupation groups. However, in order to simplify the presentation of results in this study, we aggregate the database to 25 sectors and a single representative household. The source data was adapted for use in a CGE framework by the Department of Economics at the University of Pretoria. ${ }^{1}$ A stylized representation of the model's core database, highlighting the amount of detail that can be accommodated, is shown in Figure A2 of the Appendix. Dixon, Koopman \& Rimmer (2013: 60-65) describe a MONASH-style database in detail. We give a brief summary of their description in the Appendix.

The third task is solving the model using a suitable closure. Dynamic CGE models such as UPGEM are designed to quantify the effects of a policy change, or exogenous shock, to the economy, over a period of time. A good way to examine the impacts of an exogenous shock is to compute the differences between a scenario in which the shock has occurred - the policy simulation and a counterfactual scenario in which the particular shock under examination did not occur - the baseline scenario (Chappuis \& Walmsley, 2011). Results are then reported as percentage change deviations over time between the first 'baseline' simulation run and the second 'policy' simulation run. The model's closure settings, that is, the choice of exogenous versus endogenous variables, can be considerably different between the two runs. In the baseline we exogenize those variables for which reliable forecast information exists. Typically, these exogenously set variables in the baseline run include all the main macroeconomic variables, such as the components of GDP, population growth and various price indices forecast by various macroeconomic specialists. In the policy run, all the naturally endogenous variables are indeed set as endogenous, because we are interested in the impact of the policy change on them. This setting represents a more natural model closure where the variable for which the equation was written is typically set as endogenous. For this paper we use the standard baseline forecast and policy closures described in Dixon \& Rimmer (2002: 262-274). The nominal exchange rate is set as the numeraire in the policy run for all scenarios.

The fourth and final task involves proper interpretation of simulation results, drawing only on values given in the database, the underlying theory and the model closure. Section 3 of the paper will focus on this task and aim to provide an intuitive understanding of the results. Since it is not practical to describe the entire CGE methodology or UPGEM model used in this study here, readers interested in the finer details are encouraged to consult the various references, in particular Dixon, Koopman \& Rimmer (2013).

\section{Simulations}

As noted in the previous section, we run two separate simulations in order to isolate and measure the impact of any scenario. The first establishes a businessas-usual (BAU) baseline forecast of the economy in the absence of the shock

\footnotetext{
${ }^{1}$ Documentation detailing the UPGEM database building process is available from the authors upon request.
} 
under investigation. The second simulation imposes the exogenous shock on the economy, in this case, the strike in the platinum industry. Results quantifying the impact of the shock are then reported as percentage changes between the values in the baseline run and the policy run for each variable. The forecast and policy simulations are done with different closures to the model. In the forecast closure we exogenise variables that we have forecast information for, such as household consumption, and endogenise variables that are related to them, such as the average propensity to consume (APC). Shocking the model with the forecasted value of household consumption would give a resulting value for the APC. If we would then change the closure by making household consumption endogenous and the APC exogenous, we would get the same value for household consumption by shocking the value of the APC by the solution value found previously. In general, therefore, we do a baseline forecast of the economy, then change the closure of the model to the policy closure that will be used later in the policy simulation, and re-generate the baseline forecast with it.

We are now ready to apply any set of additional policy shocks to the exogenous variables. If we would run a policy simulation where no additional shocks are applied to the policy variables, the original baseline forecast values would be the result of the simulation. This makes it legitimate to interpret differences between results in the policy and baseline runs as the effects of the policy shocks.

Baseline Forecast

Figure 1 shows the macroeconomic projections for the components of GDP from the expenditure side based on IMF (2014a), National Treasury (2014) and CEPII (2012) estimates prior to the platinum mining strike in early 2014. Using these forecast values as our BAU baseline projection allows us to then run the various scenarios simulating the impact of the strike against it and estimate the deviation from this baseline caused by the strike. From these forecast values we find that cumulative real GDP growth of around $31 \%$ is predicted for the 9 year period between 2012 and 2020. This is equivalent to an annual average growth in real GDP of $3.1 \%$ over the forecast period.

Figure 2 shows the macroeconomic projections for the main components of GDP from the income side generated in the baseline forecast. Apart from increases in capital and labour, real GDP growth is also generated from technical progress or productivity gains. ${ }^{2}$ Given the relatively subdued growth in capital and labour projected over the forecast period, and taking into consideration that each contribute roughly half of gross value added (GVA) at factor cost and around $90 \%$ of GDP at market prices combined, we can easily deduce that the contribution of technical change to the projected real GDP growth of $31 \%$ must be close to half of it.

On an industry level, we find that industry output typically follows the performance of the main macro variable with which it has the closest association. Primary and secondary industries which are export intensive such as mining and selected manufacturers are therefore expected to perform in line with projected

\footnotetext{
${ }^{2}$ Another contributor to movements in real GDP is tax carrying flows. GDP is stimulated if heavily taxed activities are stimulated. However, tax carrying flows play only a minor role in the simulations reported in this paper and will be ignored.
} 
export growth. Similarly, the construction industry's fortunes are closely tied to projections concerning investment growth in the baseline. In UPGEM, the platinum group metals (PGM) industry falls under metal ore mining which is projected to grow around $27 \%$ over the forecast period, held back somewhat by poor growth in the domestic market. Readers are reminded that these baseline projections are for the economy prior to the platinum strike.

Strike Scenarios

We design four different simulation scenarios to capture the impact of the platinum sector strike, each building on the previous with regards to the exogenous shocks imposed. This allows us to carefully analyse the impact of the different components of the shock on the economy. Since the platinum industry contributes roughly $20 \%$ of output in the metal ore mining industry, we scale all relevant shocks accordingly. The first exogenous shock we impose is holding the weighted amount of capital in the metal ores mining sector dormant for the duration of the strike. We also keep the weighted amount of overall labour in the economy dormant for the duration of the strike, but rely on the model to reduce labour at an industry level by an appropriate amount, guided by the loss in productive capital specific to the metal ores mining sector. Given the additional loss of productivity associated with restarting operations after such a long period of inactivity, we assume that the strike caused capital and labour to be unproductive, or dormant, for six months of the year, despite the strike only lasting five months. In 2015 we return capital and labour capacity to its baseline path, taking into consideration depreciation. These shocks are common to all four scenarios. Additional shocks regarding wages, investment and movements in the expected rate of return schedule for the metal ores mining industry vary between the four scenarios.

Our modelling of investment in the affected industries and of expected rates of return need some explanation. The external shock that we apply to the capital stock in the metal ores mining industry in 2014, namely to decrease the stock by $10 \%$ (a half year loss in 20 per cent of the broader metal ore mining industry's capital), causes the rental rate of capital in the industry to shoot up, much higher than the cost of buying another unit of capital - the cost of investment in the industry. Under normal circumstances investors would therefore be keen to invest in this industry because their expected rates of return are high.

In reality, however, there is not a shortage of capital in the metal ores mining industry; the available level is low because the strike causes capital to become idle. To control for this in the first two scenarios (S1 \& S2), we peg the level of investment demand in this industry to its baseline value, i.e., we do not allow extra investment in 2014, despite the fact that expected rates of return are high. Capital growth in each industry is a positive function of the expected rate of return and when the expected rate of return is higher than the normal rate of return in any industry, the capital stock grows. Since this would be true in the metal ores mining industry, given the exogenous shocks imposed, we use a modelling trick to avoid this happening, namely we shift the capital supply curve upwards until the new expected rate of return just results in normal capital 
growth. ${ }^{3}$ In 2015 we allow the curve to return to its usual position. For the last two scenarios (S3 \& S4) we reduce investment in the metal ores mining industry by $10 \%$, only allowing the capital supply curve to return gradually. In the final scenario (S4), we actually leave the capital supply curve, or expected rate of return schedule, permanently below the baseline, simulating a permanent loss of investor confidence in the industry.

Other macro assumptions for the policy simulations, in line with typical policy closure rules described in Dixon \& Rimmer (2002: 268-274), were to keep technical change, import prices, the positions of export demand curves, tax rates and various shift variables as exogenous. That is, we do not let the evolution of these variables deviate from their baseline paths after introducing the exogenous shocks in the policy run. We also tie changes in public consumption to those of private consumption in the policy run. The nominal exchange rate was set as the numeraire. The four strike simulation scenarios are summarised in Table 1 below.

The four simulation scenarios described above build on each other. Analysts and policymakers are encouraged to use their own discretion and information that is becoming available in the aftermath of the strike to judge which scenario is likely to capture the impact of the strike in the most appropriate manner. By comparing the results between scenarios we are also able to isolate the impact of different aspects of the strike in the metal ores mining industry. For example, by comparing the results between scenarios 3 and 4 , we can isolate the potential impact of a permanent change in investor preferences as a result of the shock, as opposed to a temporary change. In the following section we report and compare the simulation results between the different strike scenarios.

Policy Simulation Results

Understanding the characteristics of the metal ores mining industry is important for understanding the economy-wide impact of the strike. The platinum group metals industry is South Africa's second largest export earner behind gold and contributes just over $2 \%$ to the country's GDP. The overall metal ores mining industry (SIC 23 \& 24), which includes platinum, sells around $70 \%$ of its output to the export market. Sales to local manufacturers of basic metals, fabricated metal products and various other metal equipment and machinery (SIC 35) make up another 20\%.4 The capital-labour ratio in the industry prior to the shock is also important. Similar to the overall trend in the mining sector, the UPGEM database shows that the metal ores industry is capital intensive.

The first round impact of the shock is to reduce productive capital in the metal ores mining industry in 2014 by $10 \%$, and also to reduce the economy wide labour supply by a number equal to $10 \%$ of the metal ores labour supply. The $10 \%$ shock is derived from the fact that the platinum industry has a 20 per cent share in the overall metal ores mining industry in UPGEM, and the strike went on for about half a year. In order to help clarify the interpretation of

\footnotetext{
${ }^{3}$ See Dixon \& Rimmer (2002: 189-194) for a detailed explanation of the capital-supply function.

${ }^{4}$ The Standard Industrial Classification codes are available at https://www.statssa.gov.za/additional_services/sic/sic.htm
} 
results, we present the impact of the various strike scenarios on metal ore mining industry output relative to the baseline in two ways. The first method shows the cumulative percentage change in the industry output variable under each scenario, including the baseline. The second, more common, method shows the impact of the shock as the cumulative percentage change between the underlying value of the industry output variable in the policy run relative to its value in the baseline, under each scenario. The results for the first method are shown in Table 2 and Figure 3, and for the second method in Table 3 and Figure 4. Moving forward, we will use only the latter method to present and explain simulation results.

As shown in Table 3 and Figure 4, metal ore mining industry output is reduced by similar amounts in the first year of the shock across all scenarios, falling by between $8.4 \%$ and $8.8 \%$ relative to the baseline in 2014 . The impact of the shock on the metal ores industry takes into account the weighted share of the platinum group metals industry within this sector. Since the shocks are imposed from 2014, there are, of course, no deviations between the policy and baseline simulations in 2012 and 2013. The slightly different results between scenarios in 2014 are due to the additional exogenous shocks regarding investment (capital creation) in the metal ores mining industry, discussed in the previous section, in later scenarios. However, the bulk of the impact in 2014 across all scenarios is driven by the $10 \%$ reduction in productive capital in the metal ores mining industry, accompanied by the overall reduction in labour available to the economy at large. Differences between the strike scenarios become more apparent from 2015 onward, especially with regard to industry investment and employment outcomes.

We shock the capital stock in the metal ores mining industry by negative $10 \%$, and therefore expect that under the assumption of constant returns to scale, fixed K/L ratios and no change in technology, a 10\% decrease in capital stock should transform into $10 \%$ decreases in employment and industry output. ${ }^{5}$ However, the results show that labour demand only decreases by $7 \%$, while the metal ores mining industry output decreases by $8.5 \%$ on average.

Our simulation results show that the scarcity of metal ores mining output lets its price shoot up by $5.8 \%$ in 2014 , relative to the baseline, which directly increases the value of the marginal product of labour. In the second half of the year the mines are worked harder than usual by increasing labour hours and hence the labour/capital ratio. If capital decreases by $10 \%$ and labour by $7 \%$, then industry output should decrease by a number between 7 and 10, which it does, falling by around $8.5 \%$ in 2014 .

The macro results for 2014, shown in Table 5 for each of the four strike scenarios, respectively, show a real GDP decline of between 0.72 and 0.78. This equates to a decline in real GDP (2011 prices) in 2014 alone of between R22.87 billion and R24.64 billion relative to the baseline. These impacts follow from the reduction in capital and labour (S1, S2, S3, S4), the increase in wages

\footnotetext{
${ }^{5}$ The nominal wage, $\mathrm{W}$, is equal to the value of its marginal product: $\mathrm{W}=\mathrm{P}_{c} \mathrm{~F}(\mathrm{~K} / \mathrm{L})$, where $\mathrm{P}_{c}$ is the price of the commodity. If $\mathrm{W}$ and $\mathrm{P}_{c}$ are fixed, then a $10 \%$ decrease in capital (K) will lead to a $10 \%$ decrease in labour (L).
} 
(S2, S3, S4) and the reduction in investment (S3, S4) exogenously imposed in the respective scenarios. With technical change exogenous in the policy run, the impact on real GDP from the income side is close to a weighted sum of changes to capital and labour. Since the metal ores mining industry is a capital intensive industry, the impact on economy-wide capital in 2014 is slightly more severe than on aggregate labour, even in the scenarios where the wage shock is included. As expected, investment expenditure in 2014 is down significantly in S3 and S4 compared to S1 and S2, contributing to the slightly larger deviations seen in real GDP under these scenarios.

The macro results for 2015 show a surprisingly strong recovery in real GDP, especially in S1 and S2. How can it be that private consumption and employment in the policy run in 2015 are slightly higher than in the base run for 2015 ? What is the 'good news'?

Results from Table 5 show that in 2015 real private and public consumption increase by $0.41 \%$ above the baseline forecast value, while total investment decreases to $0.22 \%$ below the baseline in the same period (S1). Increases in consumption are usually regarded as welfare gains, but how could a five month strike be good news for the economy by leading to welfare gains in the macro economy? If we look deeper we find that there are no welfare gains. Even though we keep investment in the metal ores mining industry constant in 2014, total investment demand in the economy decreases by $1.1 \%$ in 2014 - more than real GDP. Construction goods form the bulk of the composition of any industry's investment expenditure, and the overall decrease in investment demand in this simulation has a direct impact on the construction industry: investment in the construction industry decreases by $14.5 \%$ and industry output by more than $1 \%$ in 2014. The construction industry therefore starts 2015 with a low level of capital, relative to the baseline.

From 2015 onwards, investment is necessary to rebuild the capital stock in various industries and the overall economy. The construction industry starts from a low capital base in 2015, but it is in high demand when all other industries spend on investment goods. The result is that the price of construction goods rises significantly, to $3.8 \%$ above the baseline value. The price rises particularly sharply because the industry is capital intensive and we assume a low primary factor substitution elasticity. That means we cannot easily substitute labour for capital, which makes the industry supply curve inelastic. An increase in demand for construction goods therefore leads to a large increase in its equilibrium price. This influences the value of the investment price index for 2015, which rises to $1.8 \%$ above the baseline value.

In contrast to the large increase in the investment price index, the consumer price index only rises by $0.6 \%$. South Africans are assumed to spend a fixed proportion of their nominal income on consumption and save the rest. To determine the real values of consumption and saving the nominal values are divided by the price indices described above, and if the investment price index is three times as large as the consumer price index, then the real value of saving will decrease relative to the real value of consumption. What looks like a welfare gain when real consumption is increasing in 2015 is actually bad news for South 
Africa: we are delving into our savings to buy consumption goods.

The macro results for 2016 are more negative in the later scenarios (S3, S4) given the additional exogenous shocks imposed in these scenarios. From S1 and S2, a rebound effect occurs after the strong recovery in 2015 after which we observe a gradual recovery to just under the baseline in 2020. Both S1 and S2 leave cumulative real GDP at $0.01 \%$, or around R600 million, below the baseline in 2020. This relatively small amount may be expected given the temporary nature of the shock under these scenarios. However, for S3 and S4, the impact of the reduction in investment expenditure and investment demand schedule in the metal ore mining industry further exacerbates the damage done from the strike. For S3, the expected rate of return schedule is returned to base by 2016, allowing investment expenditure and capital growth to recover in the aftermath of the strike. However, for S4, damage to investor confidence in the metal ores mining industry is assumed to be permanent, leading to investment expenditure remaining below base for the entire simulation period. The impact on real GDP in S4 is naturally more severe than in S3. The difference between the temporary and permanent impact on investment, and subsequently capital stock growth, causes the deviation in real GDP to increase between the two scenarios up to 2020 . Whilst real GDP recovers to only $0.05 \%$ below the base in S3, the worst case scenario sees real GDP down by $0.13 \%$ in 2016 and $0.15 \%$ in 2020 .

On a macro level, beyond 2016, all scenarios apart from S4 show a gradual recovery back towards the baseline. This highlights the dependency of the medium term impact of the strike on how investors assess changes to the risk profile of the mining sector in South Africa. Initial indications in the lead up to and aftermath of the 2014 strike are that investors are definitely affected, with some of the large platinum producers already announcing plans to restructure their operations according to local news reports. (The Mail and Guardian reported on 8 September 2014 that "Possible restructuring looms on the horizon for each of the effected companies - Anglo American Platinum, Impala Platinum and Lonmin"). ${ }^{6}$

On an industry level, we explain the impact on their output by grouping industries into categories. The first category is those industries directly affected by the strike. These include the metal ores mining industry itself, those industries it buys most of its inputs from, and those industries it sells most of it output to. The impact on metal ores production has already been discussed, falling by between $8.4 \%$ and $8.8 \%$ in 2014 before recovering. In S3 and S4, which we may interpret as the more likely or realistic scenarios, the impact is more prolonged with metal ore mining production down $1.2 \%$ and $2.3 \%$ cumulatively relative to base, respectively, by 2020 . The basic iron and steel manufacturing industries are relatively hard hit. These industries suffer because of their links to the metal ores industry. The shock to the metal ores industry raises its output prices, as described above, negatively impacting industries that require it

\footnotetext{
${ }^{6}$ http://mg.co.za/article/2014-09-08-platinum-mining-has-become-a-guessing-game-forinvestors
} 
as intermediate inputs within the manufacturing sector, and are at the same time trade exposed. (If they are not trade exposed they could just pass on the higher input costs to the consumers). Basic iron and steel buy almost half of their intermediate inputs from the metal ores mining industry and export $45 \%$ of their production.

With metal ores mining production negatively affected due to the strike, industries that rely on selling their output to the metal ores industry will also suffer relatively more. In this regard, the SIC 35 group of industries are significantly affected again, explaining why they are one of the biggest losers as a result of the strike. The construction industry is another relatively big loser, especially in S3 and S4, due to the industry's direct linkage to poor investment or capital creation performance. Outside of these industries with large direct links to the metal ores industry, or a particular macro variable such as aggregate investment in the case of construction, most other industries perform in line with GDP.

\section{Conclusion}

In early 2014, prior to the platinum mining strike, the real GDP growth forecast for South Africa was 2.7\% (Treasury, 2014; IMF, 2014a). The October 2014 edition of the IMF's World Economic Outlook revised this forecast down to $1.4 \%$ (IMF, 2014b). We find in this paper that real GDP growth decreased by at least $0.7 \%$ as a result of the strike alone, in 2014, and our analysis therefore suggests that more than half of the downward revision might be attributed to the economy-wide impact of the platinum strike alone.

The first observation that we made from our modelling simulations was that the effect on total industry activity in metal ores mining was slightly smaller than expected. We thought that we could take the amount of capital that lay dormant and the number of labourers that stayed at home and calculate the pro rata effects on industry production. The model showed, however, that stopping the industry from working for a period of time would make its produce scarce and push its price up in the world markets. The higher prices increased the marginal product of labour in the industry and caused the mines to employ more labour in the second half of the year, and work the mines harder than usual. Instead of decreasing by $10 \%$ - which was the downward shock to the capital stock - labour demand therefore only fell by $7 \%$ and industry production by around $8.5 \%$ for 2014 .

The second fact that emerged from the modelling simulations was that the country's overall investment situation was severely negatively affected, and not

only investment in the mineral ores mining industry. The daily news was full of the possible effects of the strike on metal ores and the broader mining industry, but our results show that the effects are much wider than this. In the first two scenarios we optimistically kept investment in the metal ores industry at its baseline levels. In the last two scenarios investment was reduced by $10 \%$. The mineral ores industry is relatively large in the South African context. It forms 
more than 5 per cent of the total final demand in the economy and letting so much of the capital and labour from the industry lay idle for half a year has large knock-on effects. Total investment demand in the economy decreased by more than $1 \%$ in 2014. Since the construction industry contributes half of all intermediate commodities used for investment purposes, it was severely affected, with its output decreasing by $1.55 \%$ in the worst case scenario.

The third and final conclusion from the paper is that investor confidence plays a very important role in the modelling results. The higher nominal wages that were one of the primary reasons for the strike and even the investment situation described above seem to affect the economy only temporarily. Most if not all industry and macroeconomic variables return to their baseline values within a few years. However, if investor confidence receives a blow as a result of the protracted strike in the mining sector, our modelling results show that the damage rendered to the economy of South Africa could be permanent.

\section{References}

[1] Adams, P.D. (2005) Interpretation of Results from CGE Models such as GTAP. Journal of Policy Modeling, 27:941-959.

[2] Anglo American Platinum Limited, Impala Platinum Holding Limited and Lonmin Plc. (2014) Producers Reach Agreement with AMCU. Press Release Issued on Behalf of Amplats, Implats and Lonmin available online at www.platinumwagenegotiations.co.za. Johannesburg, 24 June 2014.

[3] Armington, P.S. (1969) A Theory of Demand for Products Distinguished by Place of Production. International Monetary Fund Staff Papers, XVI:159178.

[4] CEPII. (2012) The Great Shift: Macroeconomic Projections for the World Economy at the 2050 Horizon. CEPII Working Paper 2012-03. Centre D'Etudes Prospectives Et D'Informations Internationales, Paris.

[5] Chappius, T. and Walmsley, T.L. (2011) Projections for World CGE Model Baselines. GTAP Research Memorandum No. 22. Center for Global Trade Analysis, Purdue University.

[6] Dixon, P.B. and Rimmer, M.T. (2002) Dynamic General Equilibrium Modelling for Forecasting and Policy: A Practical Guide and Documentation of MONASH. North-Holland, Amsterdam.

[7] Dixon, P.B. and Rimmer, M.T. (2005) Reducing the Barriers to Entry in Dynamic CGE Modelling. Paper Prepared for the 8th Annual Conference on Global Economic Analysis in Lübeck, Germany.

[8] Dixon, P.B., Koopman, R.B. and Rimmer, M.T. (2013) The MONASH Style of Computable General Equilibrium Modeling: A Framework for Practical Policy Analysis, in PB Dixon \& DW Jorgenson (eds), Handbook 
of Computable General Equilibrium Modeling, Volume 1A, Elsevier, UK, pp. 23-103.

[9] Harrison, W.J. and Pearson, K.R. (1996) Computing Solutions for Large General Equilibrium Models using GEMPACK. Computational Economics, 9:83-127.

[10] International Monetary Fund. (2014a) World Economic Outlook, January 2014. Washington, D.C.

[11] International Monetary Fund. (2014b) World Economic Outlook, October 2014. Washington, D.C.

[12] Johansen, L. (1960) A Multi-Sectoral Study of Economic Growth. NorthHolland, Amsterdam.

[13] National Treasury. (2014) Budget Review 2014. National Treasury, Pretoria. Published on 26 February 2014 and available online at www.treasury.gov.za

[14] South African Reserve Bank. (2014) Quarterly Bulletin June 2014. Statistical Tables. South African Reserve Bank, Pretoria.

[15] Statistics South Africa. (2014a) Gross Domestic Product, Fourth Quarter 2013. Statistical Release P0441. Statistics South Africa, Pretoria.

[16] Statistics South Africa. (2014b) Gross Domestic Product, Second Quarter 2014. Statistical Release P0441. Statistics South Africa, Pretoria. 
Table 1: Policy scenarios to simulate the effects of the mining strike:

\begin{tabular}{|c|c|c|}
\hline \multicolumn{3}{|c|}{$\begin{array}{c}\text { Scenario } 1 \text { (S1) } \\
\text { Direct Impact of Strike Only without Wage Settlement }\end{array}$} \\
\hline 2014 & 2015 & $2016-2020$ \\
\hline $\begin{array}{l}\text { Reduce productive capital in the } \\
\text { mineral ores mining industry by } \\
10 \% \text {, and reduce total labour } \\
\text { supply by } 10 \% \text { of the number of } \\
\text { workers in this industry. Keep } \\
\text { investment in the industry at its } \\
\text { baseline level. }\end{array}$ & $\begin{array}{l}\text { Reinstate the capital and labour } \\
\text { held dormant in } 2014 \text { to form } \\
\text { part of the available supply, and } \\
\text { fully return the expected rate of } \\
\text { return schedule of the metal } \\
\text { ores mining industry to its } \\
\text { baseline path. }\end{array}$ & $\begin{array}{l}\text { No further exogenous } \\
\text { shocks; endogenous } \\
\text { variables react to shocks in } \\
\text { the first two periods. }\end{array}$ \\
\hline \multicolumn{3}{|c|}{$\begin{array}{c}\text { Scenario } 2(\mathrm{~S} 2) \\
\text { Impact of Strike with Wage Settlement }\end{array}$} \\
\hline $\begin{array}{l}\text { Increase nominal wages in the } \\
\text { metal ores mining industry by the } \\
\text { settlement amount, added to the } \\
\text { shocks of S1 above. }\end{array}$ & $\begin{array}{c}\text { Same shocks as in S1, except } \\
\text { that nominal wages remain at } \\
\text { the higher levels negotiated in } \\
2014 .\end{array}$ & $\begin{array}{l}\text { No further exogenous } \\
\text { shocks; endogenous } \\
\text { variables react to shocks in } \\
\text { the first two periods. }\end{array}$ \\
\hline \multicolumn{3}{|c|}{$\begin{array}{c}\text { Scenarios } 3 \text { (S3) } \\
\text { Impact of Strike with Wage Settlement and Temporary Harm to Investor Confidence }\end{array}$} \\
\hline $\begin{array}{l}\text { Reduce real investment in the } \\
\text { metal ores mining industry by } 10 \% \text {, } \\
\text { added to the shocks of S2 above. }\end{array}$ & $\begin{array}{l}\text { Same shocks as in } \$ 2, \text { but only } \\
\text { move the expected rate of } \\
\text { return schedule back halfway to } \\
\text { its baseline path in } 2015 .\end{array}$ & $\begin{array}{l}\text { Fully return the expected } \\
\text { rate of return schedule to } \\
\text { its baseline path in } 2016 .\end{array}$ \\
\hline \multicolumn{3}{|c|}{$\begin{array}{l}\text { Scenario } 4 \text { (S4) } \\
\text { Impact of Strike with Wage Settlement and Permanent Harm to Investor Confidence }\end{array}$} \\
\hline Same shocks as in S3. & Same shocks as in S3. & $\begin{array}{l}\text { Move the expected rate of } \\
\text { return schedule another } \\
50 \% \text { closer to its baseline } \\
\text { path in } 2016, \text { but leave it } \\
\text { permanently below the } \\
\text { baseline. }\end{array}$ \\
\hline
\end{tabular}

Table 2: Metal ore mining industry output - baseline and policy (cumulative percentage change from 2011)

\begin{tabular}{|c|ccccccccc|}
\hline INDUSTRY OUTPUT & $\mathbf{2 0 1 2}$ & $\mathbf{2 0 1 3}$ & $\mathbf{2 0 1 4}$ & $\mathbf{2 0 1 5}$ & $\mathbf{2 0 1 6}$ & $\mathbf{2 0 1 7}$ & $\mathbf{2 0 1 8}$ & $\mathbf{2 0 1 9}$ & $\mathbf{2 0 2 0}$ \\
\hline $\begin{array}{c}\text { Baseline } \\
\text { Policy }\end{array}$ & 1.09 & 2.45 & 4.61 & 7.47 & 10.98 & 14.74 & 18.67 & 22.57 & 26.45 \\
Scenario 1 & 1.09 & 2.45 & -4.27 & 7.44 & 10.80 & 14.60 & 18.55 & 22.49 & 26.40 \\
Scenario 2 & 1.09 & 2.45 & -4.52 & 7.15 & 10.41 & 14.10 & 17.96 & 21.83 & 25.69 \\
Scenario 3 & 1.09 & 2.45 & -4.48 & 6.55 & 8.92 & 12.75 & 16.84 & 20.90 & 24.93 \\
Scenario 4 & 1.09 & 2.45 & -4.48 & 6.55 & 8.95 & 12.34 & 16.00 & 19.71 & 23.46 \\
\hline
\end{tabular}


Table 3: Metal ore mining industry output - percentage deviation from baseline

\begin{tabular}{|c|ccccccccc|}
\hline INDUSTRY OUTPUT & $\mathbf{2 0 1 2}$ & $\mathbf{2 0 1 3}$ & $\mathbf{2 0 1 4}$ & $\mathbf{2 0 1 5}$ & $\mathbf{2 0 1 6}$ & $\mathbf{2 0 1 7}$ & $\mathbf{2 0 1 8}$ & $\mathbf{2 0 1 9}$ & $\mathbf{2 0 2 0}$ \\
\hline Scenario 1 & 0 & 0 & -8.49 & -0.03 & -0.16 & -0.12 & -0.10 & -0.07 & -0.04 \\
Scenario 2 & 0 & 0 & -8.73 & -0.30 & -0.51 & -0.56 & -0.60 & -0.61 & -0.61 \\
Scenario 3 & 0 & 0 & -8.69 & -0.86 & -1.85 & -1.74 & -1.54 & -1.36 & -1.20 \\
Scenario 4 & 0 & 0 & -8.69 & -0.86 & -1.82 & -2.09 & -2.24 & -2.33 & -2.37 \\
\hline
\end{tabular}

Table 4: Selected industry output - percentage deviation from baseline

\begin{tabular}{|l|rrrrrrr|}
\hline INDUSTRY OUTPUT & $\mathbf{2 0 1 4}$ & $\mathbf{2 0 1 5}$ & $\mathbf{2 0 1 6}$ & $\mathbf{2 0 1 7}$ & $\mathbf{2 0 1 8}$ & $\mathbf{2 0 1 9}$ & $\mathbf{2 0 2 0}$ \\
\hline Metal Ores Mining & & & & & & & \\
\hline Scenario 1 & -8.493 & -0.028 & -0.160 & -0.123 & -0.101 & -0.073 & -0.045 \\
Scenario 2 & -8.727 & -0.299 & -0.514 & -0.558 & -0.597 & -0.610 & -0.606 \\
Scenario 3 & -8.689 & -0.856 & -1.855 & -1.737 & -1.538 & -1.364 & -1.203 \\
Scenario 4 & -8.689 & -0.856 & -1.825 & -2.092 & -2.244 & -2.334 & -2.372 \\
\hline Construction & & & & & & & \\
\hline Scenario 1 & -1.011 & -0.375 & 0.056 & 0.041 & 0.073 & 0.088 & 0.097 \\
Scenario 2 & -0.916 & -0.352 & 0.036 & 0.026 & 0.061 & 0.081 & 0.095 \\
Scenario 3 & -1.555 & -1.224 & -0.241 & 0.078 & 0.125 & 0.170 & 0.193 \\
Scenario 4 & -1.555 & -1.224 & -0.554 & -0.370 & -0.289 & -0.216 & -0.155 \\
\hline Basic Iron \& Steel & & & & & & & \\
\hline Scenario 1 & -1.569 & -0.779 & -0.289 & -0.189 & -0.110 & -0.061 & -0.024 \\
Scenario 2 & -1.627 & -0.761 & -0.318 & -0.243 & -0.187 & -0.156 & -0.131 \\
Scenario 3 & -1.361 & -0.683 & -0.913 & -0.672 & -0.576 & -0.475 & -0.388 \\
Scenario 4 & -1.361 & -0.683 & -0.723 & -0.688 & -0.714 & -0.726 & -0.730 \\
\hline
\end{tabular}


Table 5: Selected macroeconomic output - percentage deviation from baseline

\begin{tabular}{|c|c|c|c|c|c|c|c|c|c|c|c|c|}
\hline \multirow[t]{2}{*}{ MACRO VARIABLES } & \multicolumn{3}{|c|}{ Scenario 1} & \multicolumn{3}{|c|}{ Scenario 2} & \multicolumn{3}{|c|}{ Scenario 3} & \multicolumn{3}{|c|}{ Scenario 4} \\
\hline & 2014 & 2015 & 2020 & 2014 & 2015 & 2020 & 2014 & 2015 & 2020 & 2014 & 2015 & 2020 \\
\hline Real GDP & -0.73 & 0.04 & -0.01 & -0.72 & 0.04 & -0.01 & -0.78 & -0.02 & -0.05 & -0.78 & -0.02 & -0.15 \\
\hline Real GNE & -0.78 & 0.29 & 0.02 & -0.72 & 0.27 & 0.04 & -1.06 & -0.02 & 0.07 & -1.06 & -0.02 & -0.02 \\
\hline Consumption & -0.67 & 0.41 & -0.01 & -0.63 & 0.38 & 0.02 & -0.86 & 0.27 & 0.02 & -0.86 & 0.27 & 0.01 \\
\hline Investment & -1.11 & -0.22 & 0.11 & -1.00 & -0.21 & 0.11 & -1.75 & -1.16 & 0.22 & -1.75 & -1.16 & -0.13 \\
\hline Exports & -1.37 & -0.44 & -0.07 & -1.47 & -0.43 & -0.15 & -1.04 & -0.18 & -0.37 & -1.04 & -0.18 & -0.58 \\
\hline Imports & -1.46 & 0.34 & 0.03 & -1.41 & 0.29 & 0.00 & -1.86 & -0.17 & 0.01 & -1.86 & -0.17 & -0.17 \\
\hline Capital & -0.89 & -0.09 & -0.03 & -0.88 & -0.09 & -0.04 & -0.89 & -0.16 & -0.11 & -0.89 & -0.16 & -0.26 \\
\hline Labour & -0.69 & 0.16 & 0.00 & -0.67 & 0.15 & 0.00 & -0.78 & 0.08 & -0.02 & -0.78 & 0.08 & -0.07 \\
\hline Real Wages & -0.11 & -0.02 & -0.12 & -0.10 & -0.02 & -0.1 & -0.15 & -0.11 & -0.23 & -0.15 & -0.11 & -0.34 \\
\hline GDP Deflator & -1.34 & 1.10 & 0.01 & -1.30 & 0.95 & -0.04 & -1.87 & 0.59 & -0.02 & -1.87 & 0.59 & -0.06 \\
\hline GNE Deflator & -1.56 & 1.02 & 0.01 & -1.53 & 0.87 & -0.06 & -2.05 & 0.54 & -0.08 & -2.05 & 0.54 & -0.15 \\
\hline Real Devaluation & 1.36 & -1.10 & -0.02 & 1.32 & -0.95 & 0.04 & 1.92 & -0.60 & 0.02 & 1.92 & -0.60 & 0.05 \\
\hline Terms of Trade & 0.86 & 0.15 & 0.03 & 0.91 & 0.16 & 0.08 & 0.76 & 0.10 & 0.19 & 0.76 & 0.10 & 0.31 \\
\hline Consumer Prices & -1.32 & 0.63 & 0.03 & -1.29 & 0.54 & -0.03 & -1.66 & 0.26 & -0.03 & -1.66 & 0.26 & -0.11 \\
\hline Capital Rental Prices & -1.01 & 1.77 & 0.14 & -0.96 & 1.55 & 0.11 & -1.76 & 1.19 & 0.31 & -1.76 & 1.19 & 0.50 \\
\hline Capital Creation Prices & -1.83 & 1.80 & 0.00 & -1.74 & 1.60 & -0.03 & -2.59 & 1.17 & -0.02 & -2.59 & 1.17 & -0.03 \\
\hline Change in Trade Deficit (Rm) & -12360 & 7413 & 1440 & -11100 & 6525 & 1336 & -20021 & -3111 & 3302 & -20021 & -3111 & -1057 \\
\hline Change in Budget Deficit (Rm) & -40115 & 51041 & -965 & -39917 & 47008 & -2859 & -49927 & 45975 & -3595 & -49927 & 45975 & -556 \\
\hline
\end{tabular}


Figure 1: GDP expenditure components in baseline forecast (cumulative percentage change)

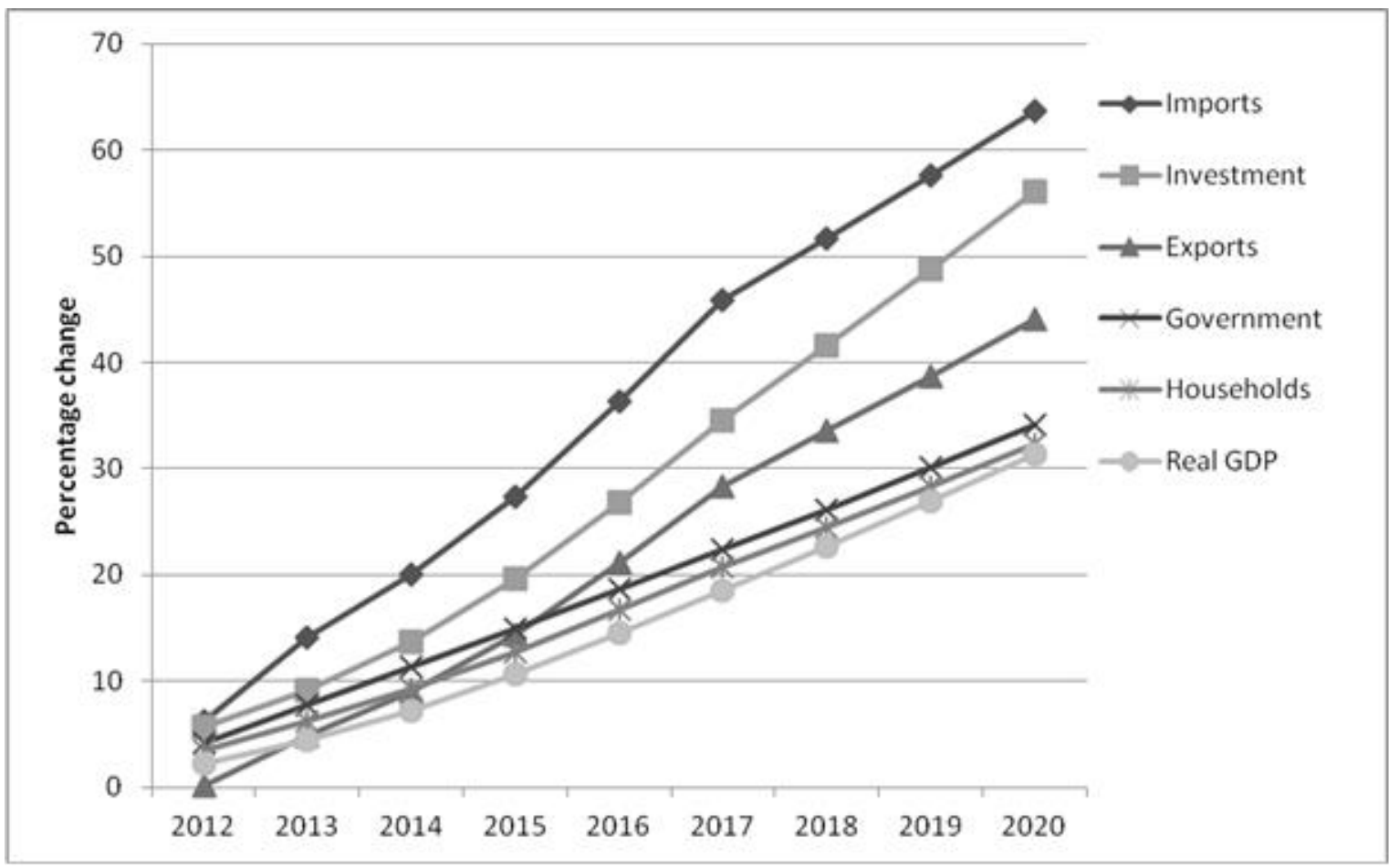

Figure 2: GDP income components in baseline forecast (cumulative percentage change)

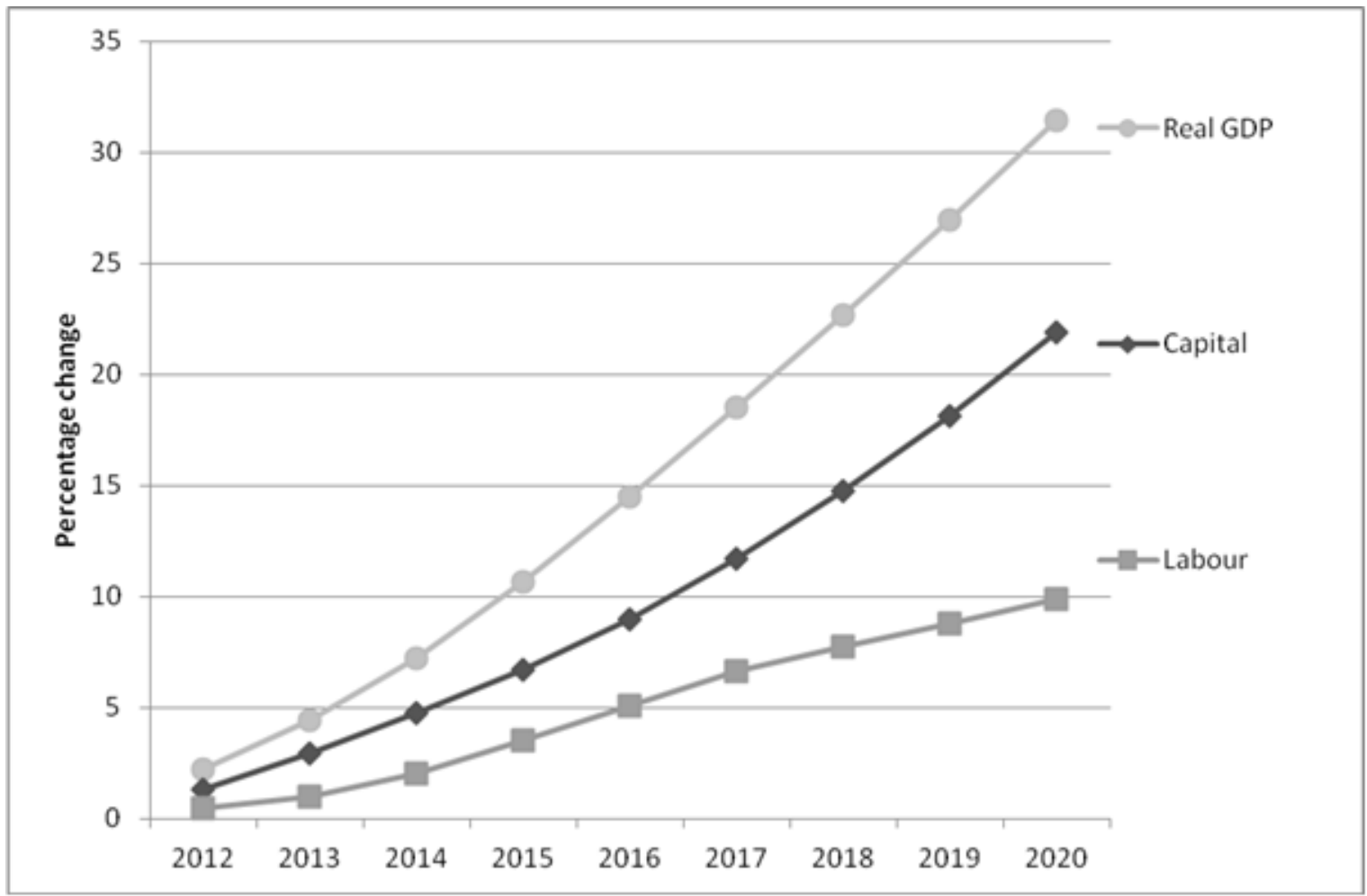


Figure 3: Metal ore mining industry output - baseline and policy (cumulative percentage change from 2011)

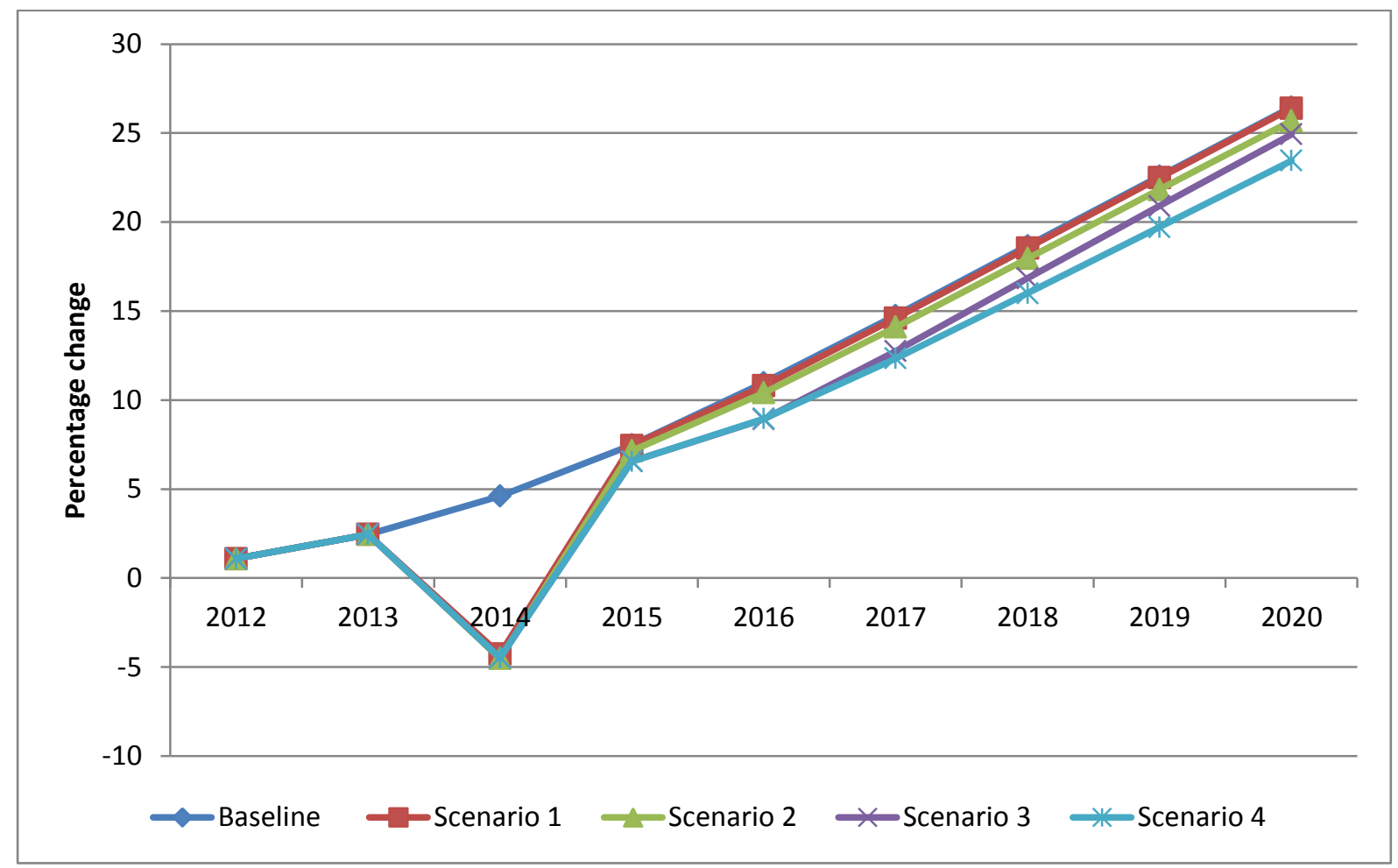

Figure 4: Metal ore mining industry output - percentage deviation from baseline

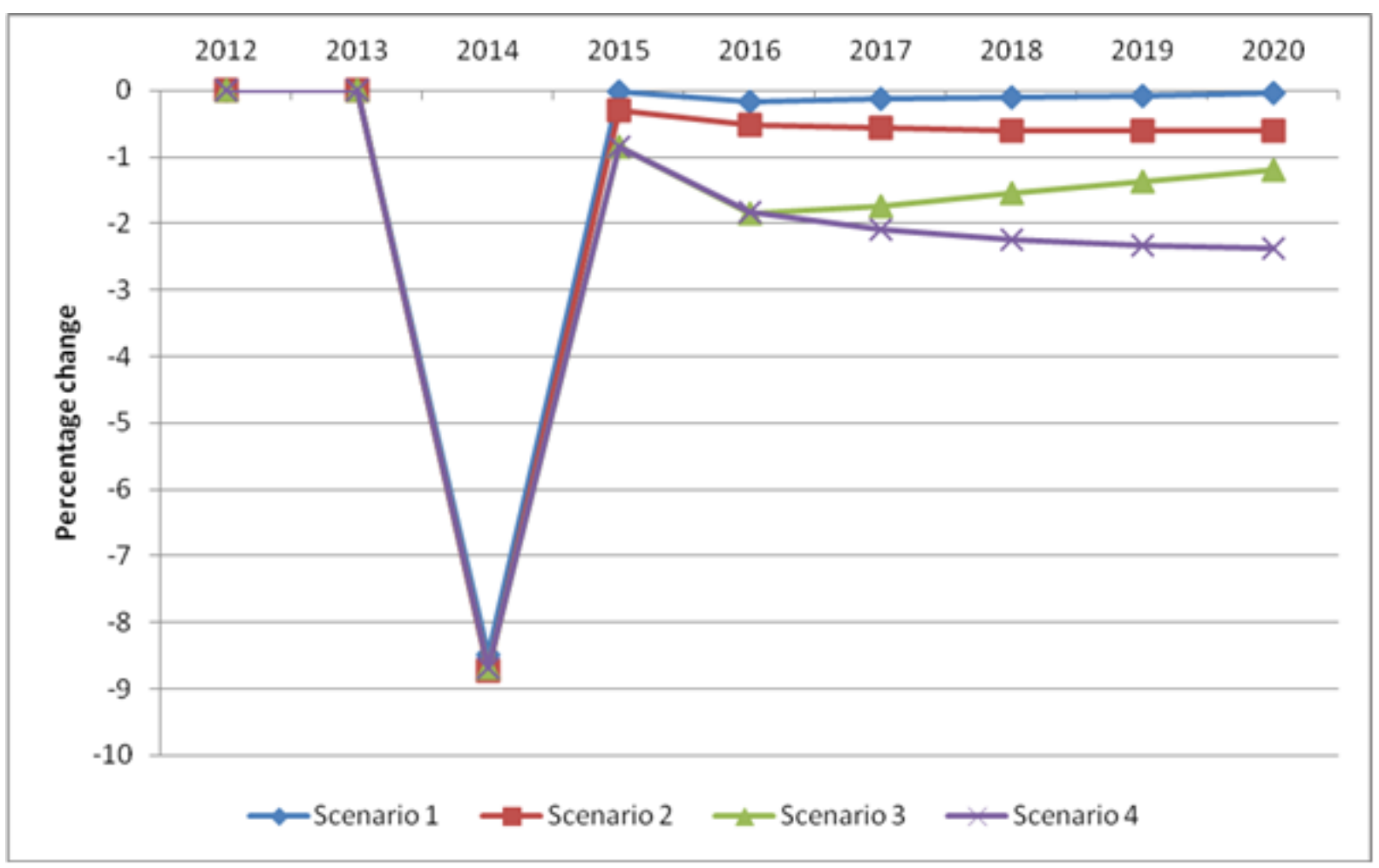




\section{Appendix}

Figure A1: Nested production structure of a representative industry in UPGEM

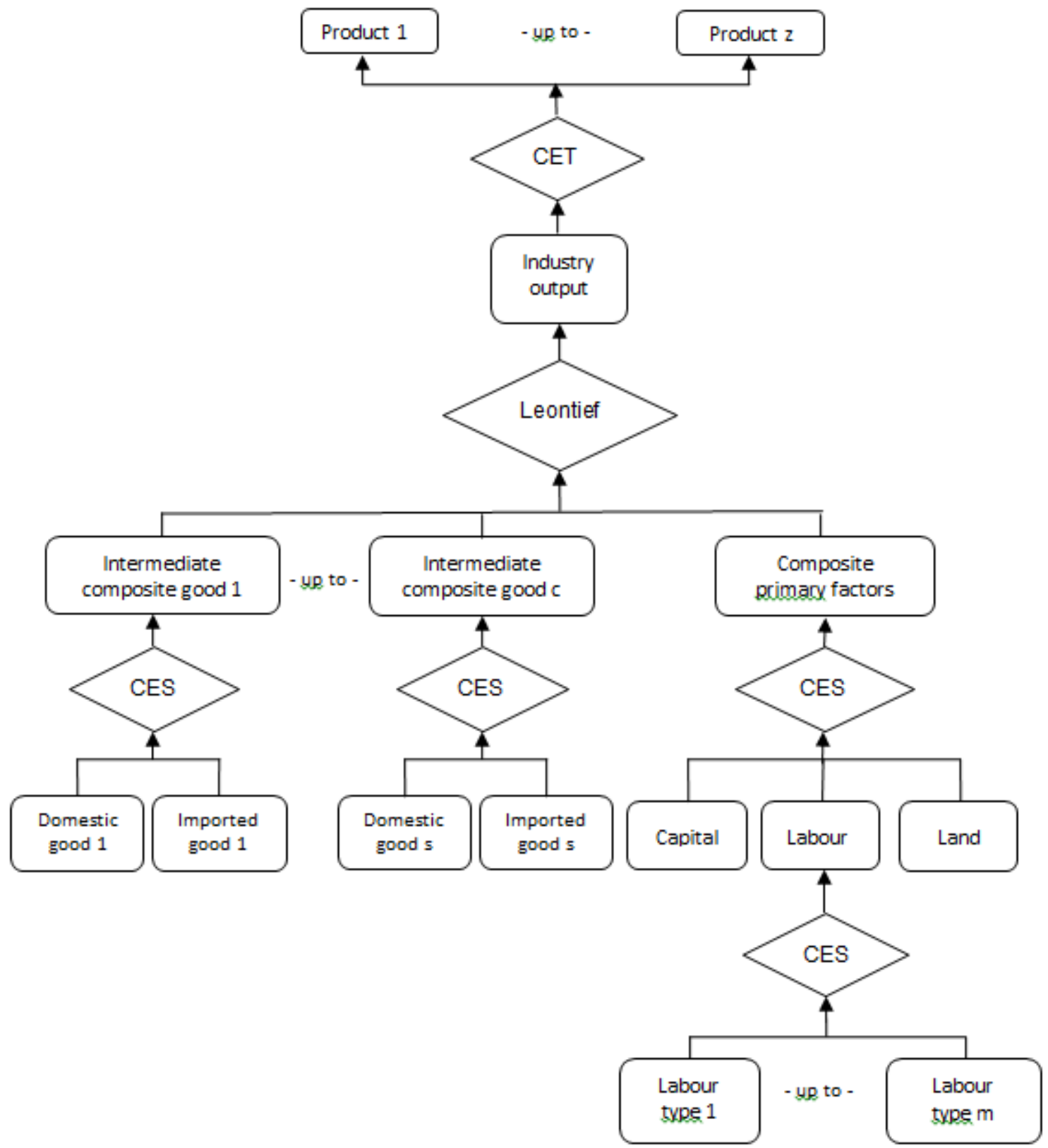


Figure A2: Stylized representation and description of the core UPGEM database

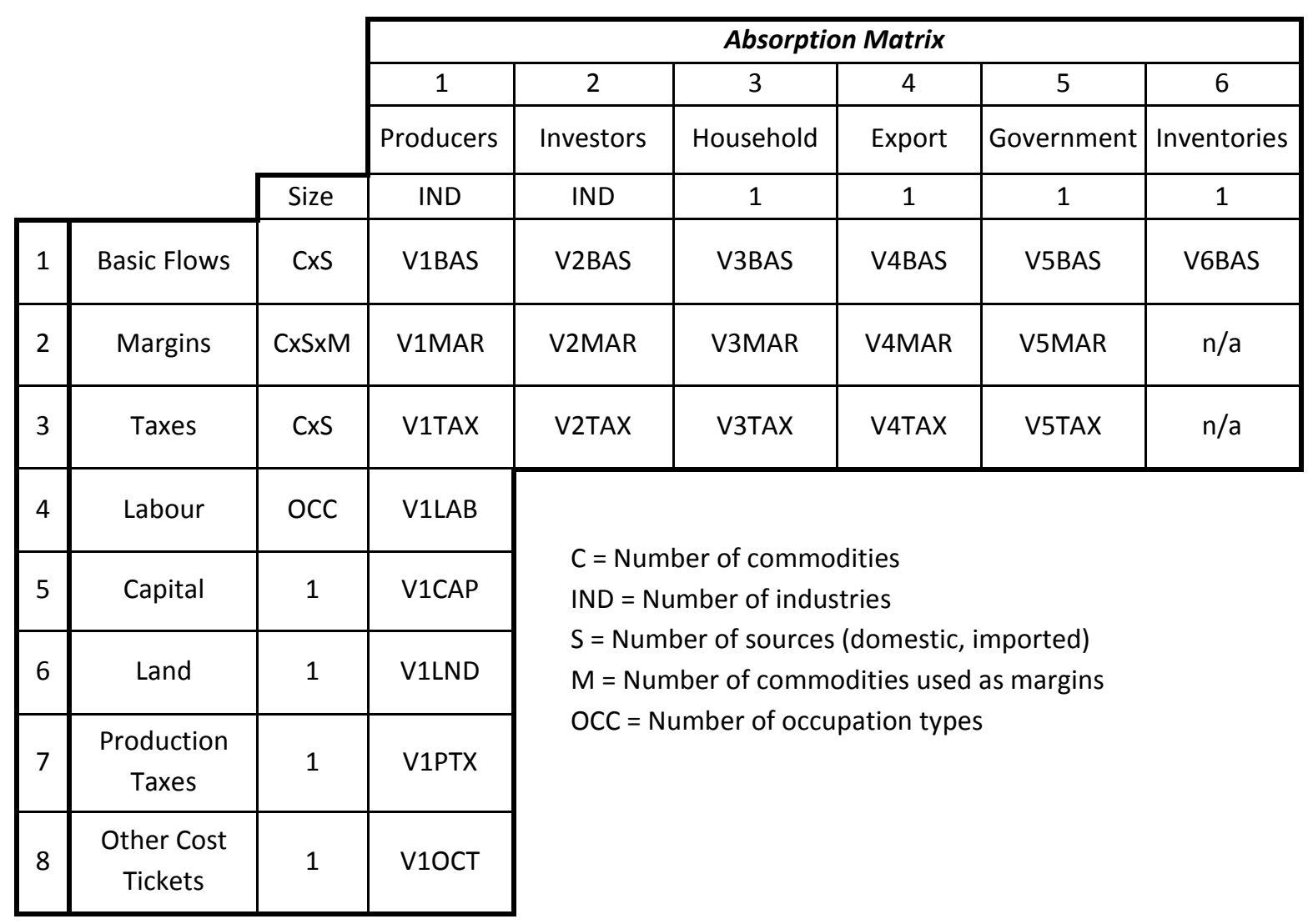

\begin{tabular}{|c|c|}
\cline { 2 - 2 } \multicolumn{1}{c|}{} & $\begin{array}{c}\text { Joint Production } \\
\text { Matrix }\end{array}$ \\
\hline Size & IND \\
\hline C & MAKE \\
\hline
\end{tabular}

\begin{tabular}{|c|c|}
\cline { 2 - 2 } \multicolumn{1}{c|}{} & Tariff Revenue \\
\hline Size & 1 \\
\hline COM & VOTAR \\
\hline
\end{tabular}

The data in Figure $\mathrm{A} 2$ has three parts: an absorption matrix; a joint-production matrix; and a vector of import duties. The first row in the absorption matrix, V1BAS, ..., V6BAS, shows flows in the base year of commodities to producers, investors, households, exports, public consumption and inventory accumulation. Each of these matrices has $\mathrm{C} \times \mathrm{S}$ rows, one for each of $\mathrm{C}$ commodities from $\mathrm{S}$ sources. (Dixon, Koopman \& Rimmer, 2013, Section 2.4.3).

V1BAS and V2BAS each have IND columns where IND is the number of industries. The typical component of V1BAS is the value of good $i$ from source $s$ used by industry $j$ as an input to current production, and the typical component of V2BAS is the value of $(\mathrm{i}, \mathrm{s})$ used to create capital for industry j. As shown in Figure A2, V3BAS to V6BAS each have one column, which refers to one representative household, one foreign buyer, one category of public demand and one category of inventory demand. These dimensions can be extended if necessary. 
All of the flows in V1BAS, ..., V6BAS are valued at basic prices. The basic price of a domestically produced good is the price received by the producer (that is the price paid by users excluding sales taxes, transport costs and other margin costs). The basic price of an imported good is the landedduty-paid price, i.e., the price at the port of entry just after the commodity has cleared customs.

Costs separating producers or ports of entry from users appear in the input-output data in the margin matrices and in the row of sales-tax matrices. The margin matrices, V1MAR, ..., V5MAR, show the values of two margin commodities used in facilitating the flows identified in V1BAS, ..., V5BAS, namely trade and transport services. The sales tax matrices V1TAX, ..., V5TAX show collections of indirect taxes (positive) or payments of subsidies (negative) associated with each of the flows in V1BAS, ..., V5BAS.

Payments by industries for 11 occupational groups are recorded in the matrix V1LAB, while payments by industries for the use of capital and land are recorded in the vectors V1CAP and V1LND. The vector V1PTX shows collections of taxes net of subsidies on production. The vector V1OCT captures other costs not elsewhere classified, where appropriate.

The final two data items are VOTAR and MAKE. VOTAR is a vector showing tariff revenue by imported commodity. The joint-product matrix, MAKE, has dimensions CXIND and its typical component is the output of commodity $c$ by industry $i$, valued in basic prices.

Together, the absorption and joint-production matrices satisfy two balancing conditions. First, the column sums of MAKE (values of industry outputs) are identical to the values of industry inputs. Hence, the j-th column sum of MAKE equals the j-th column sum of V1BAS, V1MAR, V1TAX, V1LAB, V1CAP, V1LND and V1PTX. Second, the row sums of MAKE (basic values of outputs of domestic commodities) are identical to basic values of demands for domestic commodities. If $i$ is a nonmargin commodity, then the $i$-th row sum of MAKE is equal to the sum across the (i, "dom")-rows of V1BAS to V6BAS. 